\title{
Article
}

\section{A concept analysis of befriending}

\author{
Balaam, Marie-clare
}

Available at http://clok.uclan.ac.uk/11220/

Balaam, Marie-clare ORCID: 0000-0003-4511-7352 (2014) A concept analysis of befriending. Journal of Advanced Nursing .

It is advisable to refer to the publisher's version if you intend to cite from the work.

http://dx.doi.org/10.1111/jan.12553

For more information about UCLan's research in this area go to

http://www.uclan.ac.uk/researchgroups/ and search for < name of research Group $>$.

For information about Research generally at UCLan please go to http://www.uclan.ac.uk/research/

All outputs in CLoK are protected by Intellectual Property Rights law, including Copyright law. Copyright, IPR and Moral Rights for the works on this site are retained by the individual authors and/or other copyright owners. Terms and conditions for use of this material are defined in the policies page.

\section{CLoK}

Central Lancashire online Knowledge www.clok.uclan.ac.uk 
A Concept Analysis of befriending 


\begin{abstract}
.
Aim. To report an analysisof the concept of Befriending

Background.Befriending is anintervention used in a range of nursing, health and social care settings to provide supportfor individuals who are socially isolated or lack social support. Howeverin many cases befriending and its impact remains poorly understood and under researched. Concept analysisprovides clarification of the concept andbasis for further research and development.
\end{abstract}

Design.Concept analysis

Data Sources.AMED, Psyc Articles, Psych Info, Medline, MedlinePlus, Social Science Index and CINHAL databases were searched for literature published between 1993 and2013 using the search term Befriending.

Methods.Walker and Avant's method of concept analysis was chosen. This combined with insights from Risjord's work produced a theoretical concept analysis which focused on the concept in peer reviewed academic literature.

Results. There are currently several ways the mechanisms of befriending and its effects on individuals and communities are understood. It is possible however to identify key attributes which define the concept and differentiate it from related concepts, such as peer support and mentoring. Key attributes are that it is an organised intervention, involving the creation of an emotionally connected friend-like relationshipwhere there is a negotiation of power.

Conclusion. This concept analysis has clarified current understandings and uses of befriending. It provides the basis for widening the focus of research into the effectiveness and impact of befriending on those who are befriended, those who befriend and the communities where befriending takes place. 
Keywords.befriending, concept analysis, nursing, social support, friendship, social inclusion, social capital, public health, loneliness,

\section{SUMMARY STATEMENT}

\section{Why is this research or review needed?}

- Lack of social support and social isolation are areas of considerable interest to professionals working in nursing, public health and social care.

- Befriending is increasingly used in several settingsto provide emotional and social support to individuals who, for a range of reasons are socially isolated and lack social support.

- Concept analysis can clarify how befriending is currently understood in the settings where it is used and provide a basis for further development and evaluation of befriending as an intervention.

\section{What are the key findings?}

- There are severalways where the mechanisms and effect of befriending on individual and communities are currently understood.

- Befriending is overwhelmingly seen as a positive intervention by participants in studies reviewed in the analysis, but there are some concerns overthe effectiveness of overall evaluation strategies. 
- Attributes of befriending can be identified as involving a friend-like relationship, an organised intervention and a negotiation of power and agency in the relationship.

How should the findings be used to influence policy/practice/research/education?

- The concept analysis provides the basis for further research into the mechanisms of befriending and the development of effective evaluation strategies.

- Further research should be done on the effect of befriending on those who volunteer to be befrienders and on the communities where befriending takes place. 


\section{INTRODUCTION}

Social support and its relationship to the health and well-being of individuals has been an area of considerable interest to researchers and policy makers. Researchers have explored the impact of different types of social support on health, health behaviours and overall wellbeingas part of wider concerns with the social determinants of health and the role of prevention and early intervention in health and social care (Callaghan \& Morrissey 1993, Hogan et al. 2002, Charlesworth 2007, McLeod et al. 2008,Croezenet al. 2012).Research has also identified that certain groups including the elderly (Windle 2011, Age UK 2010), people with poor mental health (Bronowski \& Zaluska 2008,Mead 2010), carers (Stoltz 2004, Thomsonet al. 2007), people with disabilities (Dean \&Goodlad 1998, Heslop 2005) and refugees (Roberts \& Harris 2002, Squire \& James 2009) have low levels of social support and increased incidence of social isolation and loneliness, all of which have a negative impacton physical and mental health (Windle 2011).Attempts to address the implications of these findings and broader concerns around health inequalities and social exclusion have led to the development of a range of targeted interventions to provide social support to those individuals deemed to be at higher risk of a range of negative outcomes(Hogan et al. 2002, Dennis 2003, Reid 2006, Charlesworth 2007, Windle2011).These interventions, some professionally provided, others community and peer based, have taken a range of forms including peer support both individual and group, peer education, mentoring and befriending (Hogan et al. 2002, Coulter \&Ellins 2006, Small et al. 2011).

\section{Background}

Befriending has been used as an intervention to support individuals with low levels of social support in a range of health and social care settings in Europe, North America and Australia(Dean \& Goodlad 1998,Behnia 2007,Charlesworth 2007, Spratt 2007, Mentoring 
\&Befriending Foundation 2009, Lester et al. 2012). Data collected in the United Kingdom by the Mentoring and BefriendingFoundation suggest that it is an increasingly popular form of intervention, with over 3,500befriending projects in the UK alone (Mulvhill 2011). Despite this increasing popularity, several reports have argued that befriending remains poorly understood, under resourced and under researched (McGowan\& Jowett 2003, Spratt 2007). Concern has been expressed over the lack of clear understanding of what befriending is, how it differs from other interventions, its mechanisms and a clear identification of the populations for whom it is most effective (Mead 2010, Mitchell 2011). Studies have noted that while those who participate in befriending projects speak very highly of their experiences (Heslop 2005, MacDonald 2010, Windle 2010), there is a lack of clear evidence to demonstrate the impact of befriending in a more systematic, standardised or rigorous way due to the lack of effective evaluation strategies (Pawson 2004, Good 2005, Meier 2008, MacDonald 2010, Mead 2010).

Concept analysis as Baldwin (2008) has argued 'can provide a knowledge base for practise by offering clarity and enabling understanding'(p.50).Risjord (2009) asserts that undertaking a concept analysis'makes the meaning of a concept explicit, so that it can be part of testable and practical nursing theories' (p. 684). The purpose of this concept analysis is to explore the concept of befriending as it is used in contemporary nursing, health and social care literature to provide a clearerunderstanding of the concept and to provide a basis from which future befriending projects can be developed and measured.

This concept analysis uses the methodology set out by Walker and Avant (2011). Walker and Avant's method follows an eightstep procedure, which includes identifying the concept, aims and purpose of the analysis, establishing all uses of the concept, determining the defining attributes of the concept, constructing a range of cases including model, borderline, contrary and relatedto further clarify the concept,identifying antecedents and consequences and 
finally, where appropriate, defining empirical referents. This concept analysis focuses on peer reviewed academically published articles providing what Risjord (2009) identifies as a theoretical concept analysis whose focus is to 'represent concepts as they appear in particular scientific literatures'(p.688).

\section{Data Sources}

An electronic search using the key word befriending was undertaken in seven databases relevant to medicine, health and social care; AMED, Psyc Articles, Psych Info, Medline, Medline plus, Social Science Index, CINHAL. The inclusion criteria for the search were peer reviewed articles, written in English and published between January 1993 and July 2013.

\section{Data selection and analysis}

The search (Figure 1) identified 147 titles. The abstracts for these articles were then located and reviewed. Duplicates were removed as were abstracts with no relevance to the study, leaving 79 articles which were then obtained as full text. Initial analysis of these articles demonstrated the range of settings where befriending has been used. They included studies relating to older adults, carers, mental illness and mental health, bereavement, suicide prevention, as well as behavioural psychology, professional-client relationships, vulnerable families, individuals with learning difficulties and refugees.

No formal method of quality assessment was used as it was important to include the widest range of possible articles in the initial analysis. Each article was reviewed in detail to ensure relevanceto the topic of the concept analysis; 14 articles were selected (Table 1), as they focused on befriending as an active social support intervention, included a definition of befriending as well as some evaluation or analysis of the nature of befriending or its mechanisms. 


\section{RESULTS}

\section{Definition}

The Oxford English Dictionary (OED 2013) identifies befriending as a noun and an adjective. It is a derivative of the verb to befriend along with befriender and 'befriended'. The verb befriend is primarily defined as, 'to act as a friend to, to help, favour, to assist and promote,' with examples of usage cited in the entry from a range of literary sources from the $16^{\text {th }}$ to $19^{\text {th }}$ centuries. A second definition of befriend is offered from a more specific context of the work of the Samaritan organisation. In this definition, befriend is 'to (set out to) give the companionship and support of a friend to (a client) especially in a lay capacity' with examples of this usage beginning in 1962 and occurring primarily in literature related to their organisation(0ED 2013).

\section{Uses of the concept in literature}

Befriending in the selected literature commonly reflected a similar duality to the definitions provided in the OED. In the literature, befriendingis presented as apositive social intervention that has both an individual and a community or social focus. Befriending provides individual support through the creation of an emotionally connected one-to-one relationship; however at the same time it is also a socially based intervention addressing the interplay between the individual and the community or social setting of which they are an integral part.

Several articles conceptualise befriending as an intervention whose focus is on the individual and their well-being. In these articles the aim of befriending is to provide social support to individuals, previously identified as having specific needs or life challenges, and though this facilitate an improvement in their quality of life. MacDonald when writing about befriending young people living with Cystic Fibrosis (MacDonald 2010) identifies the aim of befriending 
as being to improve the quality of life for those young people, through providing opportunities for friendship and socialising. MacDonald (2010)identifies the nature of the one-to-one relationship between the befriender and the befriended as key and believes befriending provided a fun distraction for young people, impacting positively on their selfesteem and helped raise issues of personal importance '(p.1).Focusing on adult bereavementReid (2006) identifies befriending as providing one to one support that helps individuals cope with their grief. Here the befriender acts as 'a friendly stranger' providing a form of 'non-intrusive support, similar to what a confident or friend could provide'(p.433).A focus on the befriender as almost a friend and the importance of a trusting or friend-like, oneto-one relationship and its ability to meet the emotional needs of the befriended are also key to several other articles which focus on befriending as an intervention for those who suffer from depression, (Harris \& Causa 2006)face social isolation and loneliness (Andrewset al. 2003) and for asylum seeking and refugee women (McCarthy \& Haith-Cooper 2013).

These articles place the individual friend-like relationship and the nature of this relationship, at the centre of their understanding of befriending, however only three of them seek to explore, albeit briefly, the possible mechanisms by which the befriending relationship may have an impact on those involved (Andrews 2003, Harris \& Causa 2006, Reid 2006). Reid (2006), when considering the role of befriending for adult bereavement, considers how it can operate as a 'buffer' for individuals 'against the negative health effects of severe stress, such as that caused by bereavement' (p.433). Harris and Causa (2006), who also address the role of befriending inbereavement, use attachment theory to explain the efficacy of this form of support, arguing that befriending relationships engender a 'sense of there being at least one person there who cares enough to hear us out that keeps us going through adversity'(p.30). Focusing on befriending for isolated older people Andrews et al. (2003) relate the positive impact of befriending to its friend-like nature relating it to wider studies on the significance 
of friendship in increasing individual well-being, asserting that befriending 'delivered many of the core elements of friendship'(p. 361).

Other articles take a wider focus, in terms of befriending being conceptualised as operating on both an individual and a social level (Gillett \& Dixon 2009, Mead 2010, Catten et al. 2011, Pistrang \& Mitchell 2011, Lester et al. 2012). This is wherethe individual aspects of befriending are placed in a wider social context and linked to concepts such as social isolation, social engagement and social networks. The aim of befriendinghere is to provide emotional support to individuals to enable them to re-integrate into the society they currently struggle to actively engage with. Thusby seeing the individual as inseparable from their relationship with their social location the impact of befriending goes beyond the effect on the isolated individual.

This perspective is evident in the work of Gillettand Dixon (2009) and Catten et al. (2011) their discussions of befriending are located in the context of public health discourses aroundthe well-being and quality of life of older people. In these articles befriending is seen as a positive social intervention which enhances both the personal and social components of well-being. At an individual level befriending reduces loneliness, increases emotional wellbeing and allows individuals to re-gain confidence, this in turn helps themre-establishsocial linksand re-engage with their local communities.Both studies focus less on the nature of the one-to-one relationship and more on the way befriending can act to relocate the individual in a social setting which then in turn brings about positive outcomes.

There are several other papers which share this perspective but seek to address moreexplicitly themechanisms by which befriending may affect those involved. Studies by Mead (2010), Lester et al. (2012) and Mitchell \& Pistrang (2011) locate befriending within a rangeof psycho-social and psycho-therapeutic interventions that seek to improve individuals' 
psychological and social functioning. They seek to determine 'what occurs within befriending relationship's that contributes to bringing about (or hindering) change' (Mitchel \&Pistrang 2010 p. 152) in the individual andhow this may enable these individuals to develop, or reconnect with, social networks and sources of external social support. This in turn reduces social isolation and social exclusion and allows them to benefit from the psychological and physical benefits of social inclusion and engagement.

It is thissocially engaged aspect of befriending that is the primary focus of articles by Chambon (2001), McGowan and Jowett (2003) and Behnia(2007). These articles place befriending in the context of wider social analyses of the individual and societal impact of the social isolation and exclusion experienced by certain individuals or groups of individuals. In these articles befriending is related to concerns around the development and extension of social networks, issues of inclusion, integration and community cohesion.

McGowanand Jowett(2003) placebefriending in the context of a public health agenda which seeks to promote health and develop social capital in communities. Using ideas from social capital and social network theoriesthey focus on the impact of befriending at the community level. They assert that befriending has 'the potential to initiate, encourage and support the development of a wider range of social networks for individuals who themselves may have limited ability to manage and maintain an adequate network of supportive interpersonal relationships'(p.15) and that it'promotes community participation, creates and strengthens social networks, combats social exclusion'(p.22).

Focusing on befriending projects working with refugee communities Chambonet al. (2001) and Behina (2007)have a similar perspective to McGowan\& Jowett (2003). Befriending, for them, is essentially a collective action, even though it involves one-to-one personal befriending relationships. They focus on the changes that can be brought about in the wider 
community rather than on the benefit to the specific individual and their quality of life.

Befriending creates opportunities for individuals to develop new ties,relationships and social supportwith a community whilst simultaneously creating a supportive environment or social support system where this can take place.

\section{Defining attributes}

The defining attributes of a concept, as understood by Walker and Avant (2011), are those characteristics which are consistently associated with the concept and that act to differentiate the concept from other similar or related ones. Three defining attributes of befriendingemerge repeatedly in the literature surveyed; these are: thatbefriending is a one-to-one, friend-like relationship, that it is an organised intervention and that it involves a negotiation of power and agency between those involved. These key attributes will now be explored in more detail.

\section{A friend-like relationship}

Befriending involves the creation of a one-to-one relationship, most commonly face to face but sometimes via telephone (Mitchell \&Pistrang 2011). The relationship is like a friendship, although it is not a friendship as commonly defined, and may be best defined as friend-like (Chambon et al. 2001, McGowan\& Jowett 2003, Mitchell \& Pistrang 2010). The relationship is characterised by the development of an emotional connection between two people where one person seeks to establish a 'non directive emotion focused' (Mead 2010) social relationship providing emotional support for the other person (Gillett \& Dixon 2009,Mitchel \&Pistrang 2011).

\section{Organised intervention}


Befriending is an organised social intervention overseen by avoluntary or community based non-statutory organisation established for the purpose of facilitating befriending (McCarthy \& Haith-Cooper 2013).Individuals who want to undertake abefriending role are trained for that role (Reid 2006, MacDonald 2010) andindividuals whoit is believed would benefit from being befriended are identified by the organisation through a variety of methods. This is overwhelmingly a non-professional community based relationship. The befriending relationship is initially facilitated by a co-ordinator who introduces two individuals previously not know to each other (Chambon et al. 2001). The organisationestablishes, with the participants, agreements relating to the nature of the relationship and plays a role in overseeing the on-goingrelationship (MacDonald 2010).

Negotiation of power \& agency

All befriending relationships involve a negotiation of power and agency between the two individuals involved in the one-to-one relationship (Lesteret al. 2012). This is necessary to establish a trustful relationship, one that involves mutualcommitment and an emotional connection between the two individuals. Negotiations often included the timing and frequency of contact, the overall length of the interventionand the nature of the relationship for example, the degree of reciprocity (Mitchell \& Pistrang 2010, Lester et al.2012). Where feelings of trust, commitment and reciprocity, as defined by the two individuals have not been established the befriending relationship is commonly characterised as having been unsuccessful (Andrews et al. 2003, MacDonald 2010).

\section{Model, borderline and contrary cases}

In the Walker and Avant method of concept analysis several cases are constructed to further clarify the concept. In the following sections, model, borderline and contrary cases have been 
drawn from the literature. In this way the cases are located in the real life contexts in which befriending are currently used.

\section{Model case}

The model case, which is one that demonstrates all the attributes of the concept identified above, is provided by the Hastings befriending scheme described by McGowanand Jowett (2003). In this case one-to-one befriending relationships are facilitated by a local organisation, the Hastings Association for the Pastoral Care of the Mentally Ill (APCMI). They identify local individuals who have long standing mental health problems and who are deemed to be vulnerable and socially isolated. These individuals are referred to the scheme by a range of statutory and non-statutory agencies; they are then matched by the organisation to individuals who have previously been trained to be befrienders. These individuals meet and begin to develop and explore the nature of their relationship and build rapport that will allow them to successfully develop a befriending relationship. The relationship and its progress is supported and evaluated by the organisation throughout.

\section{Borderline case}

A borderline case is one which demonstrates some of the attributes associated with the concept but also has some significant differences(Walker \& Avant 2011).A borderline case related to befriending is one wheretheterm befriending is used to describe the incorporation of some of the characteristics attributed to befriending, particularly emotionally connected nature of the one-to-one relationship, into a professional-client relationship (Bignold 1995, Gray 2008, Mottram 2009).In these cases there is the creation of a one-to-one, emotionally connected, befriending type relationship; however it is not a relationship between two individuals brought together by an outside organisation, it is a relationship organised by a professional and is one aspect of a larger professional nursing or caring role. 


\section{Contrary case}

A contrary case isa case wherethere is an absence of the attributes of befriending previously identified. In this context a contrary case is provided by several papers where befriending is used as the control in a series of randomised controlled trails (RCTs) exploring the efficacy of Cognitive Behavioural Therapy (CBT) as an intervention in Schizophrenic and Psychotic illnesses (Sensky 2000, Shawyer 2012, Hutton 2013). Here the term befriending is used to describe a situation where a designated health professional conversed with a participant in the trial who is not receiving the CBT intervention, to provide a neutral experience against which to judge the efficacy of CBT. Here befriending is not understood to be an active intervention with specific qualities, rather it is defined negatively in that it is not CBT. In this situation the nature of the relationship and the relationship is pre-determined by the professional. The interaction is between a professional and a client and therefore is not friend-like and the individual has limited scope to be active in the negotiation of the relationship.

\section{Related concepts}

There are three concepts closely related to befriending all of which have someof the attributes of befriending but differ in key ways. These are mentoring, peer support and friendship.

Mentoring and befriending are at times used interchangeably and there can be confusion over the differences between the two concepts (MacDonald 2010). The construction and maintenance of supporting and trusting relationships overtime is essential to them both. However there are differences, while befriending focuses more on social relationships and often takes place over a longer period of time, mentoring places more emphasis on achieving determined goals as part of a time limited process (Mentoring \& Befriending Foundation 2009, MacDonald 2010, Mead 2010). 
Several attributesDennis (2003) identifies as being essential to the concept ofpeer support are common to the attributes of befriending as defined above, however there are significant areas of divergence. These primarily relate to what Giblin (1989) calls the"peerness"of peer support. Dennis (2003) describes this aspect of peer support as the need for the supportive person to 'possess experiential knowledge of a specific behaviour or stressor and similar characteristics as the target population' (p. 329). This is not necessary or common in befriending where the two individuals may come from very different backgrounds and do not necessarily have anything in common beyond the desire to be involved in the befriending relationship.

The befriending relationship shares many characteristics with a friendship, there are however differences. Friendship for McGowanand Jowett (2003) is typically 'a private, mutual and voluntary activity between two people' (p. 15)whereas befriending relationships are not private affairs as they are organised by an organisation outside of the friendship. This organisation also places limitations on the relationship, again differing from friendships. In addition friendships are usually the product of spontaneous and voluntary choice, whereas befriending relationships, while individuals choose to enter intothem; they do not choose the other person spontaneously or completely freely. Chambon et al. (2001) defines befriending relationships as 'artificial at the outset, an encounter between strangers who would not otherwise meet' (p.6).

\section{Antecedents}

In Walker and Avant's method of concept analysis antecedents are events or incidents that must occur prior to the occurrence of the concept(Walker \& Avant 2011).Antecedents for befriending relate to both beliefs and practical events. They include a belief that health and well-being are affected by a range of social determinants and that one of these is social 
support(McGowan\& Jowett 2003, Mitchell \& Pistrang 2011). This must be accompanied by a belief that lack of adequate social support has a negative impact on the health and well-being of individualsand that an active social intervention, in this case befriending, can provide social support and so increase thewell-being and quality of life of the individuals involved(Andrews et al.2003, Behina 2007, Mitchell \& Pistrang 2011, Lester et. al. 2012).Practically, an organisation that has the capacity to facilitate befriending must exist. Two individuals who want to participate in the relationship, one as a person who wants to be befriended and one who wishes to be a befriender must be identified by the organisation. The organisation must have the capacity to perform several actions to develop and support the befriending relationship, including; training one individual as a befriender, establishing the initial contact between the two individuals and monitoring and supporting the on-going relationship (MacDonald 2010, Chambonet al. 2001,McCarthy\&Haith-Cooper 2013).

\section{Consequences}

Consequences as defined by Walker and Avant are events that occur as a result of the concept. The literature surveyed identifiesbefriending as having consequences in threeareas; for the individuals who are befriended, for the communities where befriending takes place and for individuals who actas befrienders. All the papers identify befriending as having been valued by and having a positive impact on, the emotional well-being of the people who had been befriended. They identify befriending as reducing loneliness and social isolation (Gillett \& Dixon 2009, Mulvihill 2011), increasing social interactions and social networks (McGowan\& Jowett 2003, Gillett \& Dixon 2009, Mitchell \& Pistrang 2010) thereby increasing resilience (Mulvihill 2011, Mitchel \& Pistrang 2011)and reducing mild depressive symptoms (Mead 2010). Other consequences relate to the wider social impact of befriending on the community where it takes place. In some cases it is asserted that befriending is a cost effective intervention, that reduces medical and social care costs for statutory 
bodies(Mulvihill 2011, McCarthy \& Haith-Cooper 2013)that may act as an important intervention resource as part of a wider package of social care (Mulvihill 2011, McCarthy \&Haith-Cooper 2013). Additional consequences relate to the positive impact of acting as a volunteer befriender in terms of increasing social inclusion as well as individual personal development (McGowan\& Jowett 2003, Gillett \& Dixon 2009, Mulvihill 2011, McCarthy\& Haith-Cooper 2013).

\section{Empirical Referents}

Walker and Avant (2011) identify empirical referents as classes or categories to measure this concept or determine its existence in the real world. There are no common empirical measures for evaluating the impact of befriending identified in the literature.

\section{DISCUSSION}

As a result of this concept analysis a descriptive theoretical model of the ways befriending, defined according to the attributes identified above, isunderstood and deployed in the literature surveyed as been developed and is presented more detail in Figure 2 below. It demonstrates heterogeneityboth in the analysis of the mechanisms of befriending and in ways of understanding befriending and its relationship to the individual and the community. It is possible to see the ways befriending is understood in contemporary writings as a continuum as the articles analysed range fromthose which focus on the impact of befriending on the individual's immediate well-being, to those which focus on the impact befriending has on the community where it takes place while other articles include aspects of both individual and community focus. This is possibly a reflection of the range of literature which addresses 
befriending, which in itself reflects the current variety of locations and contexts where befriending is being used, including many areas of nursing, social care and public health.

This concept analysis offers nursing and related professionals a useful over view and insight into current understandings and uses of befriending as a source of social support, and highlights what it offers as an intervention and how it differs to other commonly used interventions.

\section{Strengths and limitations of the concept analysis}

Several critiques have been made of the use of concept analysis generally and of aspects of the Walker and Avant method more specifically (Paley1996, Hupcey\&Penrod2005, Risjord 2008, Lebel et al. 2014, Draper 2014). However the strength of using a theoretical concept analysis (Risjord 2008) with regards to befriending is that it provides an opportunity to more clearly articulate an idea that is spoken of in a range of contexts but rarely systematically defined thereby providing the basis for further development. One limitation with regard to the context of the survey is that it only included articles written in English which may have limited the insights generated and perspectives included.

\section{CONCLUSIONS}

This article provides an analysis of the concept of befriending found in a range of nursing, health and social care literature from the last two decades. The defining attributes of the concept of befriending has been identified as involving; a friend-like relationship, an organised intervention and a negotiation of power and agency thought an analysis of the literature. This was developed further though the construction of related, model, borderline and contrary cases. A descriptive model has been produced which provides insights into the ways befriending has been understood and used in different settings. It suggests 
waysbefriending can be conceptualised on a continuum in terms of its impact on an individual and community level, and the differing theoretical perspectives that underpin these ways of understanding.

Befriending as characterised above can provide nursing and other health professionals with a useful resource to help them provide holistic and community based support for a range of potentially vulnerable individuals. However while in the literature reviewed befriending is almost exclusively seen as beneficial there is a need for further research in this area to increase the clarity and consistency of evaluations of the outcomes of befriending to make a more effective case for the wider use of befriending as an intervention. Further research also needs to be done to consider the wider impact of befriending, looking beyond those who are befriended to those who act as befrienders and on the communities where befriending takes place as this would add to current debates around public health, social care, social capital, and volunteerism. 


\section{REFERENCES}

Age UK (2010) Loneliness and Isolation: Evidence Review. Retrieved from http://www.ageuk.org.uk/documents/en-gb/for-

professionals/evidence_review_loneliness_and_isolation.pdf?dtrk=true on 15/12/2013.

Andrews G., Gavin N., Begley S. \& Brodie D.( 2003) Assisting friendships,combating loneliness; users' views on a befriending scheme. Ageing and Society23(3), 349-362. *

Baldwin M.A. (2008)Concept Analysis as a method of inquiry. Nurse Researcher 2, 49-58.

Behnia B. (2007) An exploratory study of befriending programs with refugees: the perspective of volunteer organizations. Journal of Immigrant and Refugee Studies5(3),1-19.*

BignoldS., Cribb A. \& Ball S.J. (1995) Befriending the family, an exploration of a nurseclient relationship. Health and Social Care 3(3), 173- 180.

Bronowski P. \& Zaluska M. (2008) Social Support of chronically mentally ill patients. Archives of Psychiatry and Psychotherapy2,13-19.

Callaghan P. \& Morrissey J. (1993) Social support and health: A review. Journal of Advanced Nursing 18(2), 203-210.

Cattan M., Kime N. \& Bagnall A.M.(2011) The use of telephone befriending in low level support for socially isolated older people -an evaluation. Health and Social Care in the Community19(2), 198-206.*

Chambon A., McGrath S., Shapiro B. \& Abai M.D. (2001)From interpersonal links to webs of relations: Creating befriendingrelationships with survivors of torture and war.Journal of Social Work Research2(2), 157-171.*

Charlesworth G., Tzimoula X., Higgs P. \& Poland F. (2007) Social networks, befriending and support for family carers of people with dementia. Quality in Ageing-Policy, Practise and Research8(2), 37-44.

Coulter A. \& Ellins J. 92006) Patient-focused interventions: A review of the evidence. The Health Foundation. Retrieved from http://www.health.org.uk/public/cms/75/76/313/526/Patientfocusedinterventions.pdf?realNa me=juNCmR.pdf on 10/06/2014.

Croezen S., Picavet H., Haveman-Nies A, de Groot., L.C.\& Veer P.V. (2012)Do positive or negative experiences of social support relate to current and future health? resultsfrom a Doetinchem Cohort Study BMC Public Health12(65).

Dean J.\& Goodlad R. (1998) The role and impact of befriending, Joseph Rowntree FoundationRetrieved from http://www.jrf.org.uk/publications/role-and-impact-befriending on 02/02/2014. 
Dennis C.L. (2003)Peersupport within a health care context; a concept analysis.International Journal of Nursing Studies40,321-332.

Draper P. (2014) Editorial: A critique of concept analysis. Journal of Advanced Nursing70(6),12071208.

Fitzsimons P. (2010)Dialling up social care for older people.Working with Older People; Community Care Policy and Practise14(3),10-14.

Giblin T.P. (1989) Effective utilisation and evaluation of indigenous health care workers. Public HealthReports104(4), 361-368.

Gillett K.\& Dixon M. (2009) Vital links: nurturing emotional well-being in older people though one to one communication. Working with older people 13(4),2-23. *

Gray B. (2008) Befriending excluded families in Tower Hamlets: the emotional labour of family support workers in cases of child protection and family support. British Journal of Social Work39(6), 990-1007.

Harris T.\& Causa H. (2006) Volunteer befriending as an intervention for depression.Bereavement Care25(2), 27-30.*

Heslop P. (2005) Good practise in befriending services for people with learning difficulties. British Journal of Learning Disabilities33, 27-33.

Hogan B., Linden W.\& Najarian B. (2002)Social support interventions:do they work? Clinical Psychology Review 22,381-440.

Hupcey J. E. \& Penrod J. (2005) Concept Analysis: examining the state of the science. Research and Theory for Nursing Practice: An International Journal 19, 197-208.

Hutton P.(2013)BCT for Schizophrenia; A critical commentary.Psychology and Psychotherapy: Theory, Research and Practise86(2), 139-145.

Lebel V., Alderson M. \& Aita M. (2014) Physiological stability; a concept analysis.Journal of Advanced Nursing doi: 10.1111/jan.12391Retrieved from http://onlinelibrary.wiley.com/doi/10.1111/jan.12391/full on 15/06/2014.

Lester M., Mead N., Graham C.C, Gask L. \& Reilly S. (2012) An exploration of the value and mechanisms of befriending for older adults in England. Aging and Society 32, 307-328.*

MacDonald K. (2010)Cool friends: an evaluation of community befriending with young people with Cystic Fybrosis. Journal of Clinical Nursing117(8), 2406-14.*

McCarthy R.\& Haith-Cooper M. (2013)Evaluting the impact of befriending for pregnant asylum-seeking and refugee women. British Journal of Midwifery21(6), 404-409.*

McGowan B.\& Jowett C.(2003) Promoting positive mental health through befriending. International Journal of Mental Health Promotion59(2), 12-24.* 
McLeod E., Bywaters P. Tanner D. \& Hirsch M.(2008)For the sake of their health:older service users' requirements for social care to facilitate access to social networks following hospital discharge. British Journal of Social Work38,73-90.

MeadN. (2010)Efffects of befriending on depressive symptoms and distress: systematic review and meta analysis.The British Journal of Psychiatry196, 96-101.*

Mentoring and Befriending Foundation (2009) Transforming lives; examining the positive impact of befriending and mentoring. Mentoring \& Befriending Foundation. Retrieved fromhttp:/www.mandbf.org/wp-content/uploads/2011/03/TRANSFORMING-LIVES-FinalPDF.pdf on 12/12/2013.

Mitchell,G.\& Pistrang N. (2011)Befriending for mental health problems: process of helping. Psychology \& Psychotheraphy:Theory, Research \& Practise84, 151-169*.

Mottram A. (2009) Therapeutic relationships in day surgery, a grounded theory study. Journal of Clinical Nursing18(20), 2830-2837.

Mulvihill J.(2011)The unique and valuable support provided by mentoring and befriending. Workng with older people15(1), 34-37.*

Oxford English Dictionary. (2013) Oxford English Dictionary. Oxford University Press, Oxford. Retrieved from http://www.oed.com on 10/11/2013.

Paley J. (1996) How not to clarify concepts in nursing. Journal of Advanced Nursing 24,572578.

Reid D.(2006) Adult bereavement in five English hospices: types of support.International Journal of Palliative Nursing12(9), 430-437*.

Risjord M. (2009)Rethinking concept analysis.Journal of Advanced Nursing 65(3), 684-691.

Roberts K. \& Harris J.(2002) Disabled people in refugee and asylum seeking communties. The Policy Presss for the Joseph Rowntree Foundation, Bristol. Retrived from http://www.jrf.org.uk/publications/disabled-people-refugee-and-asylum-seekingcommunities-britain on 12/12/2013.

Sensky T. ( 2000) A RCT of CBT for persistent symptoms in Schizophrenia resistant to medication Archives of General psychiatry 57(2),165-172.

Shawyer F. ( 2012) A RCT of acceptance based CBT for command hallucinations in psychotic disorders.Behaviour Research and Therapy50(2), 110-121.

Phillip K. \&SprattJ. (2007) A synthesis of published research on mentoring and befriending for The Mentoring and Befriending Foundation. Retrieved from http://www.mandbf.org/wpcontent/uploads/2011/03/Synthesis-of-published-research-MBF-report-Kate-Philip.pdfon $10 / 02 / 2014$. 
Small, R., Taft, A. J. \& Brown S. J. (2011) The power of social connections and support in improving health: lessons from social support interventions with childbearing women. $B M C$ Public Health 11 (suppl 5), 54.

Squire C. \& James J. (2009) Refugee woman. InThe Social Context of Birth, (Squire C. ed.), Radcliffe Publishing,Oxford, pp. 93-107.

Stoltz, P., Udén, G. \& Willman, A. (2004) Support for family carers who care for an elderly person at home - a systematic literature review. Scandinavian Journal of Caring Sciences, 18: 111-119. Retrieved from http://onlinelibrary.wiley.com/doi/10.1111/j.14716712.2004.00269.x/pdf on 13/12/2013.

Thompson C.A., Spilsbury K., Hall J., Birks Y., Barnes C. \& Adamson J. (2007) Systematic review of information and support interventions for caregivers of people with dementia. BMC Geriatrics 2007, 7:18. Retrieved from http://www.biomedcentral.com/1471$2318 / 7 / 18$ on $03 / 02 / 2014$

Walker L.O.\& Avant K.C. (2011)Strategies for theory construction in Nursing, 5th edn. , Prentice Hall, Boston.

Windle K., Francis J. \& Coomber C.(2011) SCIE Research Briefing 39: Preventing loneliness and socal isolation; interventions and outcomes. Retrieved from http://www.scie.org.uk/publications/briefings/briefing39/ on 11/12/2013. 
Electronic search in AMED, Psyc Articles, Psych Info, Medline, Medline plus, Social Science Index, CINHAL using the key word/search term befriending $(\mathrm{n}=147$ abstracts $)$

\begin{tabular}{|c|c|}
\hline & $\begin{array}{l}\text { Removal of duplicates and } \\
\text { abstracts not relevant to the }\end{array}$ \\
\hline $\begin{array}{l}\text { Articles selected and reviewed in full } \\
\text { text } \\
(\mathrm{n}=79)\end{array}$ & \\
\hline $\begin{array}{l}\text { Articles selected for final inclusion } \\
\text { in the concept analysis }\end{array}$ & $\begin{array}{l}\text { The final articles selected for } \\
\text { inclusion had befriending as their } \\
\text { focus and included definitions } \\
\text { and some attempt at evaluation } \\
\text { and analysis of the nature } \\
\text { befriending or its mechanisms. }\end{array}$ \\
\hline
\end{tabular}

Figure1. Literature search and data extraction flow chart 


\title{
Table 1: Articles selected for final analysis
}

\author{
Author and year Nature of study and area of focus
}

Chambon A. et al. (2001)

Andrews G., et al. (2003)

McGowan B. \&

Jowett C. (2003)

Harris T. \& Causa

H. (2006)

Reid D. (2006)

Behina B. (2007)

Gillett K. \& Dixon

M. (2009)

MacDonald K.

(2010)

Mead N. (2010)

Cattan M. et al. (2011)

Mitchell G. \&Pistrang N. (2011)

Mulvihill J. (2011)

Lester M. et al. (2012)

McCarthy R. \& Haith-Cooper M. (2013)
Exploratory participatory study of the volunteer befriending programme for immigrants at Canadian Centre for Victims of Torture (CCVT) using interviews $\&$ focus groups with befrienders, befriendees and volunteers $(n=51)$.

Experiences of users of a home visiting befriending scheme for older adults in the UK using semi structured interviews $(n=13)$.

Literature review and service evaluation of UK community befriending scheme promoting postive mental health.

Study exploring befriending as an intervention for depression, methods including the development of a survey of women in North London $(n=400)$ and follow up interviews with selected women.

In depth organisational case studies of 5 English hospices offering befriending using qualitative interviews, focus groups \& documentary material.

Descriptive exploratory study of befriending programmes working with refugees using self administered semi structured questionnaires $(\mathrm{n}=25)$.

Service evaluation of a befriending scheme for older adults (Vital Links, UK).

Qualitative longitudinal pilot study of the impact of a community befriending scheme for young people with Cystic Fibrosis.

Systematic review \& meta-analysis of randomised control trials to examine the effectiveness of befriending on depressive symptoms and distress.

Mixed methods service evaluation of telephone befriending schemes for socially isolated older adults in the UK.

Qualitative study of the helping processes in befriending relationships for individuals experiencing metal health problems using semi structured interviews with befriendees \& befrienders in the UK $(n=23)$.

Study of the role and value of befriending for older people including a literature review and case studies from the UK.

Qualitative study to exploring the experiences of older adults who have used 5 befriending services in the UK through interviews. $(n=25)$.

Service evaluation/audit of volunteer befriending project for pregnant refugee women in a city in the UK. 
Figure 2 Descriptive theoretical model of befriending

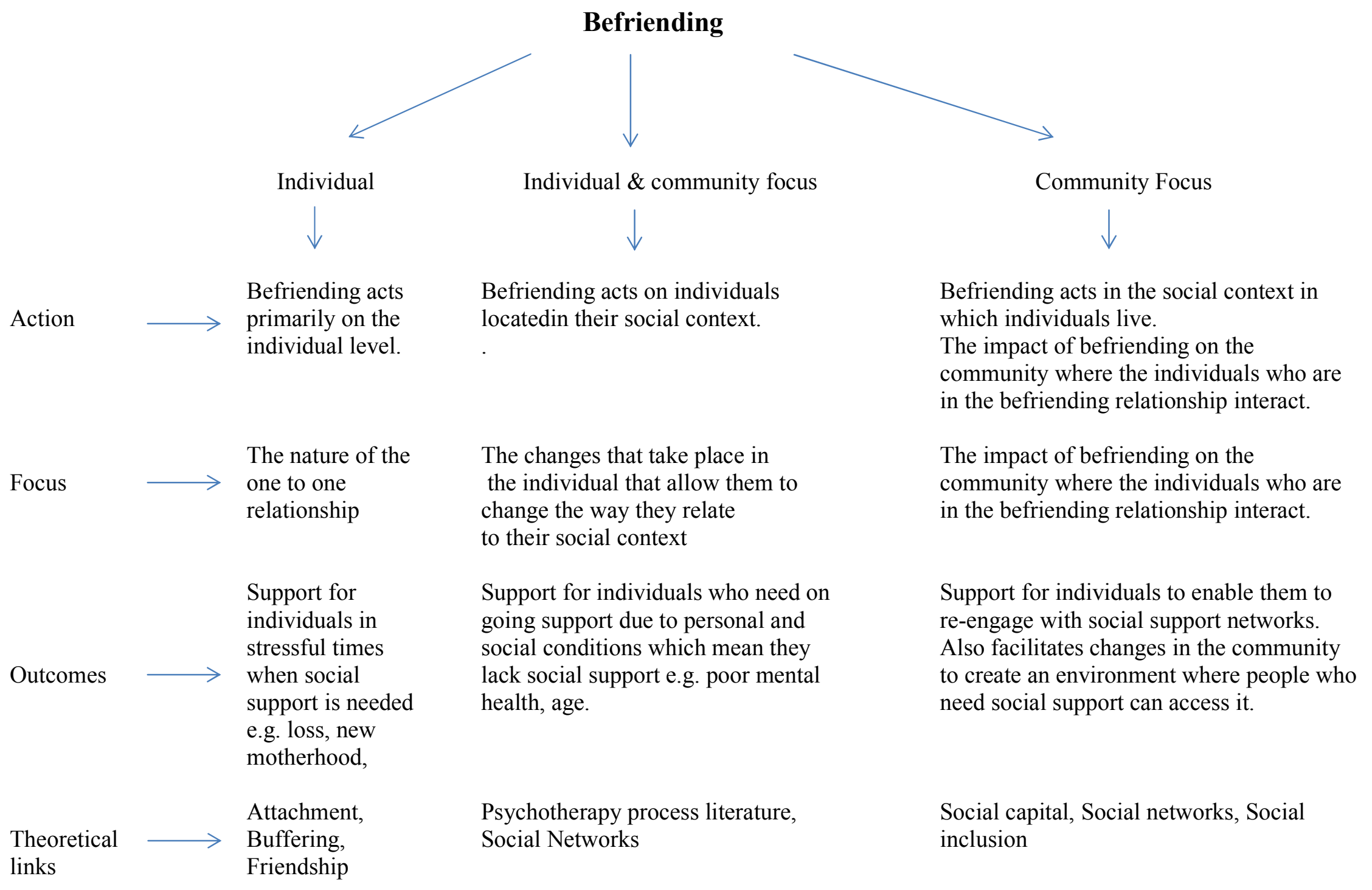


